\title{
Concepción ideográfica del espacio: La singularidad y su valor en la construcción de un mundo habitable
}

Recibido: 17 de febrero 2018 Revisado: 28 de mayo 2018 Aprobado: 26 de junio 2018

Adriana Masís Morales Costarricense. Licenciada en Arquitectura por la

Universidad de Costa Rica.

Se dedica al estudio de la arquitectura y de la filosofía, sus correspondencias e influencia sobre la relación sujeto-espacio, atendiendo los temas del habitar, la poética del espacio y el análisis crítico de la arquitectura y sus procesos de prematerialización y materialización. Actualmente, se desenvuelve de manera independiente, como consultora, diseñadora y directora de proyectos.

Correo electrónico: adrianama59@yahoo.es

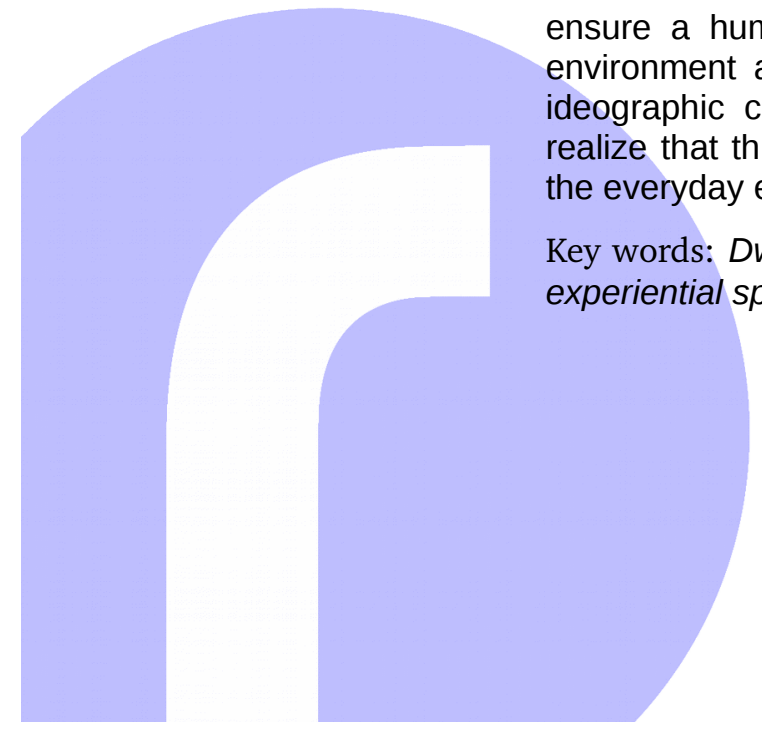

http://investiga.uned.ac.cr/rupturas/ (c) (i) (-)
Resumen: La arquitectura actúa como configuradora del espacio en el que, a pesar de que muchas variables son y deben ser cuantificadas, $y$ estrictamente controladas, también a raíz de su relación directa con los modos de vida del ser humano, está sujeta a fenómenos singulares que le impiden acudir a fórmulas arquetípicas como solución al asunto del Habitar. En consecuencia, este artículo reconoce el valor de las vivencias, la convivencia y el relato de los eventos significativos, como un tema esencial para asegurar la calidad humana en el espacio construido, la contribución en la sensibilización de nuestra sociedad con su entorno y la evolución de la arquitectura misma. Esta última, al acoger sus contenidos ideográficos, se integran en la memoria colectiva y comprende que, a través de la construcción de lugares y no-lugares, afecta directamente los eventos cotidianos de la ciudad y a quienes la habitan.

Palabras clave: Habitar; ideografía del espacio; relación sujeto-espacio; nolugar; espacio vivencial

\section{Ideographic Conception of Space: Singularity and Its Importance in the Construction of an Inhabitable World}

Abstract: Architecture takes action in the configuration of space, but in spite of the fact that many variables are and have to be quantified and strictly controlled; also as a consequence of it's direct relationship with human being's way of living. Architecture is subject to singular phenomena that prevent it from attending archetypal formulas to solve the Dwelling issue. Therefore, this article seeks to recognize the value of life experiences, cohabitation and the narration of significant events, as an essential topic to ensure a human touch in built space, help sensitize our society with it's environment and the evolution of Architecture itself; that by embracing it's ideographic contents, manages to integrate in the collective memory and realize that through the construction of places and no-places, directly affects everyday events of the city and the people who live in it.

Key words: Dwelling; space ideography; subject-space relationship; no-place; experiential space 


\section{Aprender a construir y Habitar desde la propuesta de Heidegger}

En el ensayo titulado «El arte y el espacio (Die Kunst Und Der Raum)» de Heidegger, nos encontramos con una referencia a la plástica, tanto en el sentido escultórico, como en el sentido más general de una actividad a través de la que se le da forma a una masa. Por este motivo, sus reflexiones se han ampliado al mundo de la arquitectura como aporte y referente en cuanto a la idea de espacio. Dicho espacio se entiende en términos de existencia y no de materia física. Más bien este apela al espacio vital y significativo que nos remite a los seres humanos como habitantes y actores de la vida cotidiana, en donde las representaciones $u$ obras pierden relevancia porque traducen la amplitud del concepto "espacio" a algo cuantificable y dimensionado, cuando, en realidad, el espacio es una producción que engendra y "da lugar a entornos hasta entonces desconocidos" (Heidegger 2009, 44).

Así, se podría afirmar que la arquitectura no se crea en un lugar, sino que produce un lugar, pero esa producción no se tiene que confundir con el planeamiento y la resolución físico-técnica del espacio; por el contrario, se debe entender como una producción simbólica que manifiesta nuestra propia existencia.

Con demasiada frecuencia, el vacío aparece tan solo como una falta. El vacío pasa entonces por una falta de algo que llene los espacios huecos y los intersticios (...) [Sin embargo], no es un echar en falta, sino un producir (...) [que] proyecta lugares (Heidegger 2009, 30-31).

La arquitectura da significado a 'la nada', la encapsula y la configura por medio de la materialidad, el color, las formas y muchos otros elementos; pero más que eso, genera para 'la nada' un relato capaz de mutarse y de multiplicarse por medio de las vivencias particulares de cada sujeto.

Por su parte, la lectura más superficial del espacio nos diría que se trata de la disposición de cierto conjunto de materiales lo que evoca la sensación de estar en un espacio. Esta visión mecánica nos llevaría a evaluar las cualidades y las propiedades de los materiales como proyecciones de la materia física, que crean sensaciones por sí mismas.

Claramente, no será lo mismo una pared de piedra, que una de madera, o una pared vegetal, pero este sería un acercamiento muy desabrido a todo lo que la experiencia espacial puede ser, ya que desde esta perspectiva, el aspecto de la superficie de un material, con un cierto volumen que compone a 
su vez la superficie del espacio, es el espacio mismo. En otras palabras, no habría manera de profundizar en ello más allá de las dos o tres dimensiones, pues los volúmenes quedarían entendidos como conjuntos de superficies en distintas direcciones que le dan un particular aspecto a la superficie del espacio. Esto nos limita a entender el espacio por medio de lo más evidente, que es la materia física-visible que lo compone.

Si el espacio fuese, únicamente, ese vacío rodeado de superficies que obstaculizan o preestablecen nuestra posibilidad de movernos y de cambiar de lugar, llegaríamos a una postura algo insípida de lo que el espacio por definición es, como sucede en esta enunciación:

(...) la idea de espacio es una idea abstracta: el espacio es la nada personificada o convertida en sujeto por una operación de nuestro entendimiento, para haber de explicar la facultad que tenemos de movernos cuando 'ninguna cosa' no nos lo impide, o, lo que es lo mismo, esta 'nada' nos lo permite (Destutt 1830, 77).

A pesar de esta última concepción, existe una lectura que entiende el espacio no solo como el vacío encapsulado, sino también desde fuera de esa cápsula, es decir, irradia las cualidades del afuera que se complementan con las propias del vacío. Desde ahí, es posible acceder al análisis de las articulaciones entre espacios, la posibilidad de mezclarlos o superponerlos, entre tantas otras que componen la sensación de no solo 'estar', sino de poder recorrer. Así, la idea de espacio no quiere decir solo estar dentro, sino estar fuera; mejor dicho, dentro y en medio simultáneamente respecto a distintos objetos y dependiendo de nuestra propia perspectiva. Heidegger asevera que

La configuración acontece en la delimitación, entendida como inclusión y exclusión con respecto a un límite. Aquí es donde entra en juego el espacio. El espacio es ocupado por la figura plástica y queda moldeado como volumen cerrado, perforado y vacío. [Y agrega:] ¿Acaso esta corporeiza el espacio? ¿Se adueña la plástica del espacio? ¿Es una dominación del espacio? (Heidegger 2009, 13).

A raíz de estos cuestionamientos, surge la noción de habitar como el resultado de la corporeización del espacio que, a su vez, corporeiza la existencia o "la verdad del ser" (Heidegger 2009, 32). Sin embargo, también se hace la advertencia de que esa verdad, como desolcultamiento del ser, no debe consistir en lo corpóreo, pues existen valores abstractos que son capaces de hacer notar la existencia al ser, sin necesidad de estar visibilizados en el espa- 
cio. Por esto, surge la interrogante: “(... ¿puede valer el espacio proyectado en términos técnicos y físicos como el único espacio verdadero?" (Heidegger $2009,16)$. No necesariamente. Y por este motivo, es importante ahondar en la concepción ideográfica del espacio.

En este caso, la ideografía vendría a ser la manera de acercarnos a la arquitectura, pues le da valor a la experiencia individual, única e irrepetible y aparta los instrumentos que sirven para el entendimiento universal de la arquitectura. Así, el espacio se entiende como un fenómeno que nos concientiza sobre nuestra existencia y aviva la humanidad.

\section{La singularidad del habitar como mediadora para comprender lo intangible en la producción del espacio}

Recordemos que, aunque en la mayoría de las ocasiones el espacio en la arquitectura se nos muestra como un vacío cosificado, este concepto de espacio es apenas un primer acercamiento a una noción mucho más compleja, que podemos encontrar en el análisis ideográfico del espacio. Esto último implica la posibilidad de experimentar varias perspectivas sobre las cuales construimos nuestra propia versión del espacio, lo que nos orienta a una lectura metafísica que va más allá de lo material, de toda la información axiomática que obtenemos a través de nuestros sentidos y en la constitución de los preceptos sociales que nos enseñan a asimilar el espacio.

A causa de la amplia cantidad de variables culturales, económicas y de todas las estructuras de la sociedad que afectan nuestra percepción del habitar y del construir, podríamos hablar de un amplio espectro en el área de la interpretabilidad simbólica que, en algunas ocasiones, es poco explorado, pero resulta muy necesario para darle un sentido humano a la labor de la arquitectura. Además, el espacio, entendido como 'espaciar para habitar', no quiere decir utilizar técnicas de proyección ni construir materialmente, sino revelar nuestra existencia en el mundo.

Este carácter del espaciar se pierde de vista con suma fa-

cilidad. Y cuando es visto, sigue siendo difícil determinar-

lo, sobre todo mientras el espacio físico-técnico pase por

ser el espacio al que de antemano debe atenerse toda

caracterización de lo espacial (Heidegger 2009, 23).

Por ejemplo, cuando Heidegger hace referencia a la idea de construir, no lo dice en un sentido arquitectónico, ingenieril ni siquiera técnico, pues estos valores son superficiales a su búsqueda. Él ahonda en la idea de construir como si retrocediera en el tiempo antes de que el vacío se cosificara, es decir, en el momento previo. Ese momento usualmente inexplicable ante el cual 
recurrimos al concepto de 'caja negra' para, al menos, darle un nombre al espacio 'pre-creado' o en proceso de creación.

Para este filósofo, la construcción se da no solo sobre aquello que ya de por sí tiene condición de realidad (lo que 'es'), sino también en el espacio que tiene condición de relato; por lo tanto, si bien en lo que denominamos realidad vemos un sujeto y un espacio, en la idea metafísica del construir y habitar el espacio, no se considera al sujeto como un ente independiente del espacio; por el contrario, como un conjunto que compone un relato. Ambas ideas -la de construir y la de habitar-, que la arquitectura constantemente coloca dentro del ámbito de la acción, para Heidegger, pertenecen más al campo de la reflexión y del pensamiento, por ende, según él, la creación de un espacio estaría más asociada a construir conceptos que a construir objetos.

Inclusive, deteniéndose a analizar, en términos de lenguaje, desarrolla la siguiente reflexión: “¿De qué habla el lenguaje en la palabra 'espacio’? En ella habla el espaciar. Espaciar remite a 'escardar', 'desbrozar una tierra baldía'. El espaciar aporta lo libre, lo abierto para un asentamiento y un habitar del [ser humano]" (Heidegger 2009, 21).

En este orden de ideas, nos deja la sentencia de que si somos capaces de habitar, podemos construir. Esto, en primer lugar, con la acepción de que el habitar no quiere decir que, por el hecho de existir en el espacio, todos seremos capaces de ejecutar la construcción de una obra, pero sí que el habitar es un suceso cotidiano que les permite a los sujetos contribuir con la construcción social de lo que se entiende por espacio. En segundo lugar, en un sentido más profundo, el Habitar (con H mayúscula) significaría, para los arquitectos, ser conscientes de los fenómenos del espacio, ahondar en ellos, buscarlos, imaginarlos, discutirlos y transformarlos como parte del ejercicio de Habitar.

Conjuntamente, Heidegger (2009) expresa que hay muchos espacios, como las autopistas, las fábricas, los estadios, los aeropuertos o hasta las centrales energéticas, los cuales no constituyen una morada, pero sí son parte del Habitar, pues habitar no consiste nada más en tener donde alojarse, es mucho más que eso. "Para el camionero la autopista es su casa, pero no tiene allí su alojamiento; para una obrera de una fábrica de hilados, ésta es su casa, pero no tiene allí su vivienda" (Heidegger 1994, 127). Es decir, para poder 'Habitar' no necesitamos las 'habitaciones' de una casa, ya que el espacio-mundo es la gran habitación del ser humano y eso traslada las preocupaciones por el confort y el bienestar, que eran propias de la vivienda como espacio privilegiado, al mundo. En realidad, este último es nuestro espacio para estar y existir.

Inclusive, esto llevado al controversial tema sobre la falta de viviendas (situación preocupante que regularmente es analizada como hecho cuantificable sobre quienes tienen un alojamiento residencial y quienes no) podría ser traducido por Heidegger a una consecuencia de no saber Habitar. De esta forma, puede suceder que una persona que parece tener casa no logre Habitar $\mathrm{y}$, solamente, la entienda como un alojamiento, así como una persona que no 
posee este bien - a pesar de carecer de muchas o de ninguna de las comodidades propias de la casa y utilizar alojamientos temporales-, podría llevar consigo la plena 'Habitación del mundo', por eso menciona:

Por muy dura y amarga, por muy embarazosa y amenazadora que sea la carestía de viviendas, la auténtica penuria del habitar no consiste en primer lugar en la falta de viviendas. La auténtica penuria de viviendas es más antigua aún que las guerras mundiales y las destrucciones, más antigua aún que el ascenso demográfico sobre la tierra y que la situación de los obreros de la industria. La auténtica penuria del habitar descansa en el hecho de que los mortales primero tienen que volver a buscar la esencia del habitar, de que tienen que aprender primero a habitar (Heidegger 1994, 142).

\section{El relato. Herramienta ideográfica para una transición hacia el Habitar}

Contrario a lo que comúnmente se piensa, una casa no nos garantiza que acontecerá un Habitar, pues este hecho dependerá de la posibilidad de hacer valer nuestra existencia en la casa, es decir, lo que requiere la construcción de nuestro relato con ese espacio; por ejemplo: albergar recuerdos, imaginar momentos, crear una empatía por el significado de ese lugar a un nivel simbólico. De hecho, una de las críticas que se vislumbran en el desarrollo filosófico de Heidegger es que normalmente "el habitar no es experienciado como el ser del hombre; el habitar no se piensa nunca plenamente como rasgo fundamental del ser del hombre" (Heidegger 1994, 130), y esto tiene mucho de cierto aún en nuestra época, pues se ha reducido el habitar al espacio de la casa; luego, esta se ha estandarizado al cumplimiento de ciertas configuraciones y aspectos formales y; con ello, finalmente, se ha desatinado la posibilidad de crear una experiencia que no fuera impuesta, sino construida (en el sentido heideggeriano de construir).

De hecho, Habitar es, también, expresado en términos de sensaciones, como el sentirse cuidado y sentirse libre, es como estar albergado, pero sin sentirnos atados a lo que nos alberga:

Es decir, es lo libre que cuida toda cosa llevándola a su esencia. El rasgo fundamental del habitar es este cuidar 
(mirar por). Este rasgo atraviesa el habitar en toda su extensión. Esta se nos muestra así que pensamos en que en el habitar descansa el ser del hombre, y descansa en el sentido del residir de los mortales en la tierra. Pero "en la tierra" significa "bajo el cielo". Ambas cosas significan 'permanecer ante los divinos' e incluyen un 'perteneciendo a la comunidad de los hombres' (Heidegger 1994, 131).

Así, entre la tierra, el cielo, el ser de las personas y lo divino (podrían entenderse como los fenómenos de lo ordinario y de lo prodigioso) se genera el existir, que nos da el Habitar. Bajo esta perspectiva, cada construcción edificada adquiere un carácter superior a ser, únicamente, 'la cosa en sí', pues si se trata de algo que se Habita, un aula no puede ser solo un aula, un hotel no puede ser solo un hotel ni un hospital solo un hospital. Todos ellos deberían poder escapar de su estado más aparente para congregarse en la idea de Cuaternidad (entre tierra, cielo, divinos y mortales) establecida por Heidegger, mediante la cual, su existencia en el mundo afirma la existencia del ser humano en el mundo. De esta manera, le permite a los espacios ordinarios gozar de cualidades simbólicas que les otorgan; a través de la posibilidad de relatar vivencias significativas entre espacios y seres humanos. Este sentido es ampliamente explicado con el ejemplo del puente, donde explica:

(...) el puente, ante todo y en su ser propio, es sin más un puente. Y que luego, de un modo ocasional, podrá expresar además distintas cosas. Como tal expresión, se dice, se convierte en símbolo, en ejemplo de todo lo que antes se ha nombrado. Pero el puente, si es un auténtico puente, no es nunca primero puente sin más y luego un símbolo. Y del mismo modo tampoco es de antemano sólo un símbolo en el sentido de que exprese algo que, tomado de un modo estricto, no pertenece a él. Si tomamos el puente en sentido estricto, aquél no se muestra nunca como expresión. El puente es una cosa y sólo esto. ¿Sólo? En tanto que esta cosa, coliga la Cuaternidad. 
Nuestro pensar está habituado desde hace mucho tiempo a estimar la esencia de la cosa de un modo demasiado pobre (Heidegger 1994, 135).

Construir y Habitar son dos asuntos que no suceden uno como consecuencia del otro, más bien son algo simultáneo que, desde la perspectiva heideggeriana, comprende un desenvolvimiento humanístico en el que el arquitecto no debería ser impositivo, sino — por su supuestamente desarrollado sentido del Habitar - ser capaz de construir antes que con los materiales con el relato; que, finalmente, le dará significado a la relación entre el sujeto y su espacio. En ese sentido, critica profundamente la denigración que sufre el Habitar cuando el arquitecto construye para sí mismo, pues esto debilita la pluralidad de experiencias y vivencias espaciales que son distintas para cada persona, ya que, en vez de crear para sí, podría envolverse en la posibilidad de realmente pensar la arquitectura, según su discurso titulado "Construir-HabitarPensar, se logra justamente Construyendo y Habitando".

No obstante, en algunos momentos, 'construimos' pensando en construir objetivamente 'la cosa' antes que el concepto. Y a veces, habitamos, imaginando y presuponiendo que nuestro modo de habitar es el mismo que el de los demás, o peor aún, que todos los sujetos tienen las mismas aspiraciones en términos de habitabilidad. Según nosotros, esto es lo que nos faculta para abordar objetivamente una lista de requisitos que, una vez satisfecha, lastimosamente, nos podría inducir a crear espacios mal construidos o inhabitables.

Eisenman nos ofrece una muestra de la complejidad implícita en la creación del espacio, al referirse al "Doble Zeitgeist" (Eisenman, 1995) como respuesta a un cambio de paradigma. En este último, la arquitectura ya no responde únicamente al zeitgeist o espíritu del tiempo que estaba influenciado por la gente y el lugar, sino que las experiencias suceden también en ámbitos no tan evidentes, como lo es la información. ¿Y en dónde está la información? En todas partes.

Así pues, las experiencias van aún más lejos de lo que acontece en un determinado lugar, con ciertas personas, en una época específica. Esto significa que diseñar el espacio físico inspirado en un sitio específico no es suficiente, porque el espacio físico se agota en sí mismo; en concreto, padece el problema de la inmanencia. Entonces, necesitamos comprender el doble zeigeist para romper la ideografía del espacio inmanente e ir a la búsqueda del espacio trascendente.

La Arquitectura ha respondido, por muchos años, al diseño de lo inmanente y ha logrado grandes creaciones con ello. En ese confinamiento de una realidad que se encierra en sí misma, hemos creado y recreado lo físico con todas las características propias del espacio, pero nos falta aprender del relato como herramienta para redescubrir lo poético del espacio y su trascendencia como sensación de ser en el espacio. Así, una de las maneras en las que el 
espacio escapa de sus limitantes físicos y trasciende en su significado es cuando nos relacionamos con él. Todo se relaciona; y el espacio no es la excepción.

\section{Del espacio al 'lugar', a través de la vivencia y convivencia}

Si se desea explicar el espacio de manera objetiva, habría que comenzar por presuponer que el espacio es uno solo, lo cual es posible, considerando que, al describir conjuntos de espacios, todos ellos se acaban interrelacionando a tal punto que se convierten en uno. Dicho esto, si el espacio es uno solo, lo que nos impide explicarlo objetivamente es el hecho de que el espacio no es 'en-sí'; es 'para-nosotros'. Esto significa que su existencia está dada respecto a nuestra experiencia del espacio, lo que nos conduce a que todo diálogo sobre el espacio, necesariamente, tenga un carácter subjetivo, fenomenológico e interpretativo.

A pesar de esas afirmaciones ¿sabemos si puede ser pensada la objetividad plena? ¿Si son composibles todas las perspectivas? ¿Si se pueden tematizar todas a la vez en alguna parte? ¿Sabemos si la experiencia táctil y la experiencia visual pueden coincidir rigurosamente sin una experiencia intersensorial? ¿Si mi experiencia y la del otro pueden estar vinculadas en un sistema único de la experiencia intersubjetiva? Tal vez se den, ora en cada experiencia sensorial, ora en cada consciencia, unos "fantasmas" que ninguna racionalidad puede reducir (Merleau-Ponty 1993, 235).

Estos fantasmas de los que habla Merleau-Ponty han sido recreados por Varini en sus intervenciones artísticas hechas sobre arquitecturas y contextos urbanos, en los cuales cada perspectiva de un mismo espacio nos muestra pinturas de figuras geométricas fragmentadas y abstractas, pero en las que existe una sola perspectiva que nos ofrece una composición geométrica ordenada a través de figuras legibles. En estas obras, se transfigura la noción de la intersensorialidad, pues si encontramos el ángulo correcto, veremos una imagen clara. Sin embargo, en la medida en que nos acercamos para tocar la pintura, perderemos la visión de la geometría legible. Igualmente respecto a la intersubjetividad, cada espectador se ve representado como una de las muchas perspectivas, desde las que se puede observar el espacio intervenido, pero solo uno de ellos -el que se encuentra en el punto privilegiado de la perspectiva- puede reconocer la organización de lo que, para los demás, es aparentemente caótico.

Tal acercamiento admite las muchas variables que entran en juego para que lleguemos a nuestra versión ideográfica del espacio. La ideografía denota el entendimiento de las singularidades de las cosas y puede ser transformada, eventualmente, en ideogramas, como los kanjis (signos del idioma japonés). No obstante, para llegar a dicha transformación, necesitan adquirir un uso consensuado que permite que distintas personas entiendan lo mismo al ver el ideograma. 
Figura 1. Felice Varini. Paisajes de la perspectiva e ilusiones anamórficas, 1979-2018.

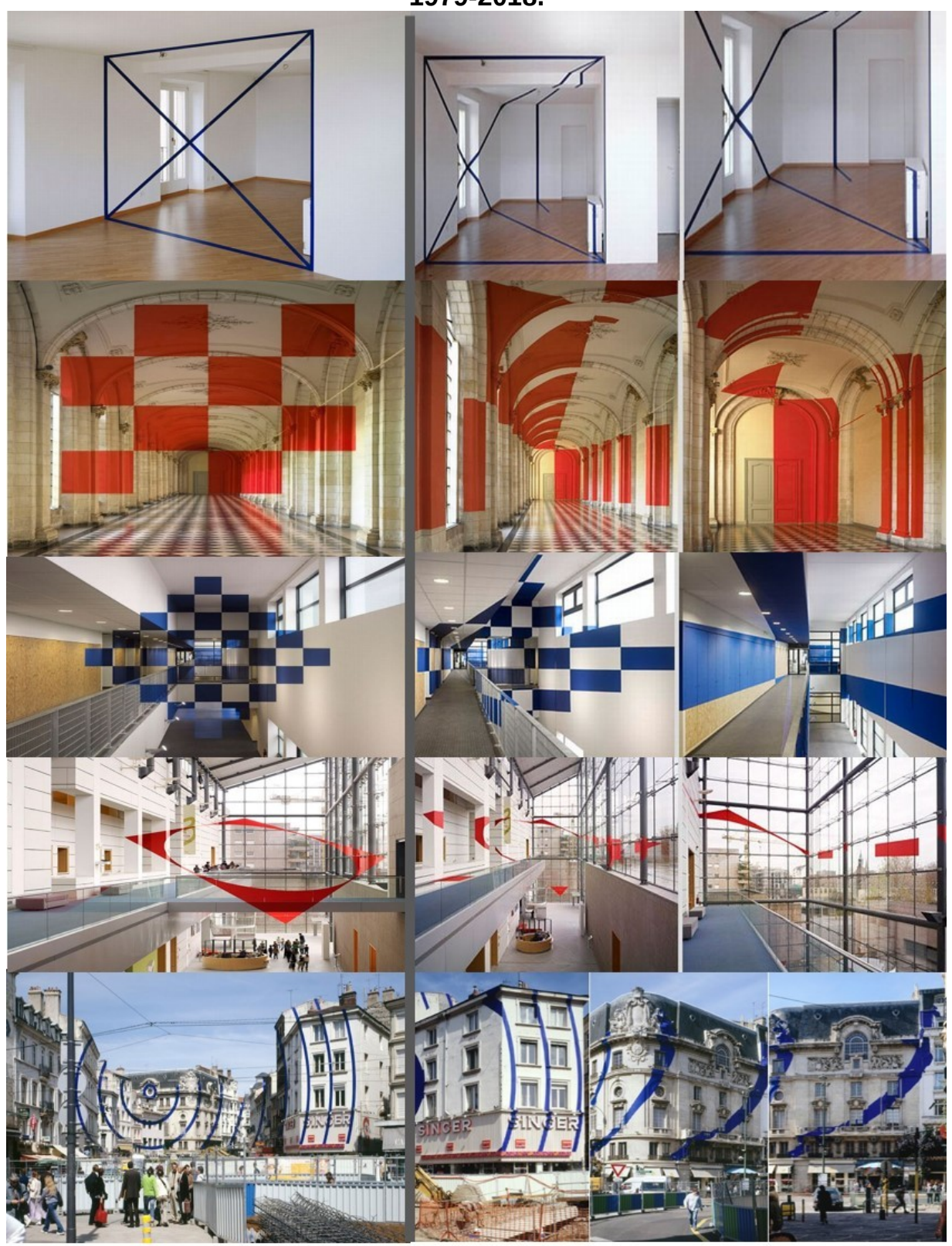

Recuperado de http://www.varini.org/varini/02indc/indgen.html

Sin embargo, el espacio, en ese caso, trata el tema de las subjetividades, las habilidades sensoriales, los sistemas de valores y las perspectivas en general. Corresponde a un concepto en constante cambio, del que solamente existen pautas gráficas en cuanto a la representación planimétrica del espacio, en términos interpretativos, experimentales y vivenciales. Le es mucho 
más beneficioso mantenerse abierto como concepción ideográfica, ya que eso le asegura su renovación y adaptación. Kahn comenta al respecto: "La Arquitectura es la estudiada construcción de espacios. La continua renovación de la Arquitectura proviene de la evolución de los conceptos de espacio" Kahn (1957, citado en Van De Ven, 1981, 11). Entonces, en la actualidad ¿cómo se manifiesta la evolución del concepto de espacio, que -como lo dice Kahn- trae implícita la evolución de la Arquitectura?

Refiriéndonos, en especial, a los espacios compartidos, por representar, con mayor facilidad, las concesiones que se viven desde la óptica de un conjunto de sujetos: sociedad, comparativamente, se diría que, por ejemplo, el espacio público solía ser 'el por qué' de la ciudad y, en la actualidad, evolucionó con una tendencia a convertirse en 'el espacio entre' la ciudad.

El reflejo actual de nuestra evolución denota dos facetas que se unifican en una sola paradoja. El espacio como distancia reducida por la existencia de medios de transporte, redes de información, circulación dinámica de grandes masas de personas y sobrepoblación que abarrota la ciudad con edificios, parqueos, apartamentos, viviendas y demás equipamientos que nos abochornan en todos los sentidos cartesianos. Con arquitecturas horizontales, verticales, subterráneas, aéreas, flotantes y móviles que crean el efecto de un espacio que se encuentra dentro de otros espacios y dentro de ellos se multiplican muchos otros que fraccionan los vacíos y nos conducen a revolvernos con nuestros vecinos, combatir límites y acogernos a una relación de mayor contacto con el espacio construido.

Y complementariamente, se nos aparece una sociedad espaciada del espacio, es decir, inmersa en entornos construidos que se esperaría que nos hicieran caer en cuenta del espacio mismo y de la existencia y convivencia con muchos otros sujetos que circulan por la ciudad. No obstante, cuyo dinamismo se adormece ante la falta de interés por la realidad que se muestra fuera de las pantallas de los artículos tecnológicos, en una dinámica urbana marcada por el individualismo y la constitución de espacios con gestos puramente estéticos que actúan fuera de contexto, sacando de escala cualquier posibilidad de convivencia. Augé (2000) agrega:

Del exceso de espacio podríamos decir en primer lugar, aquí otra vez un poco paradójicamente, que es correlativo del achicamiento del planeta; de este distanciamiento de nosotros mismos al que corresponden la actuación de los cosmonautas y la ronda de nuestros satélites.

En un sentido, nuestros primeros pasos en el espacio nos lo reducen a un punto ínfimo, cuya exacta medida nos la dan justamente las fotos tomadas por satélite (Augé, 2000 37-38). 
El espacio tiene esa particular condición que le permite impactar al sujeto y distanciarlo, así como involucrarlo; sin embargo en cuanto a conceptos, a partir de muchas visiones exitosas y otras desventajosas para la propagación de espacios vivos, nuestra situación actual nos habla del espacio como un concepto que se encuentra tan cerca, pero tan lejos; tan reconocible, pero tan invisible; tan nombrado por los arquitectos en distintas épocas, pero pocas veces interpretado y reflexionado de una manera accesible al resto de la sociedad.

A través de la construcción o producción de espacios, como un 'arte funcional' o 'arte utilitario', de acuerdo con el historiador Alois Riegl, es que la concepción ideográfica del espacio entra en contacto con la sociedad, como una respuesta a diversas problemáticas.

Bajo este argumento de la utilidad, entra en juego una mecánica de pensamiento e interacción entre el sujeto y el objeto. En unos casos, la función puede ser obvia (un comedor, un pasillo, un patio). En otros, el sujeto es quien descubre para qué sirve, tiene la oportunidad de escoger el uso del objeto (espacio) indeterminado y al igual que con el arte; esto requiere que se detenga y observe. Es, en esta paradoja, entre lo que se piensa minuciosamente para que el objeto arquitectónico responda a necesidades específicas y lo que no se piensa (espontáneo), por no dilapidar la sensatez de la intuición, que la arquitectura como concepto puede terminar suspendida, entre una rigidez que deshumaniza y el antojo desmedido.

Se trata de una acción pregnante que conlleva el diálogo entre la imagen mental y la imagen física de una obra que, a su vez, dialogará con otras mentes y otros entornos físicos. Por lo tanto, al hablar de arquitectura, se refiere de un hecho colectivo y, por eso, resulta tan difícil generar una definición, pues se trata de un concepto que se construye, entre muchos, en medio de una disparidad de contribuciones.

(...) la Arquitectura se presenta como una meditación so-

bre las cosas, sobre los hechos. Los principios son pocos

e inmutables, pero las respuestas concretas que el arquitecto y la sociedad dan a los problemas que se van planteando en el curso del tiempo, son muchísimas. La inmutabilidad viene dada por el carácter racional y reductivo de los enunciados arquitectónicos (Rossi 1977, 203-204).

La arquitectura forma parte, construye y evidencia la historia y las costumbres, al dejar huella de las formas de vida y exigencias de cada época. De hecho, ya se han sobrepasado los conceptos bajo los cuales la escala estaba supeditada a las medidas y las geometrías por sí solas. Nuestra concepción ideográfica del espacio nos dice eso, que es una composición que se debate entre la invasión del espacio personal y la sensación de encontrarnos lanza- 
dos a un espacio inmenso e impersonal. Finalmente, este dimensionamiento del concepto espacio encuentra su escala más que en el contexto, en el ser humano mismo, quien es el referente íntimo que puede regular el hecho de que un sujeto se sienta intruso en un espacio invasivo o diminuto en un espacio inmenso. En el texto de la Poética del espacio, se nos induce a reflexionar al respecto:

la inmensidad es una dimensión íntima. La inmensidad se desarrolla. Baudelaire [habla de la inmensidad en el sentido íntimo como] una de esas impresiones felices que casi todos los [seres humanos] imaginativos han conocido gracias a los sueños, mientras dormían. Me sentí liberado de los lazos de la gravedad, volví a encontrar, por medio del recuerdo, la extraordinaria voluptuosidad que circula en las altas cimas. Luego me pinté involuntariamente el delicioso estado de un hombre presa de un gran ensueño en una soledad absoluta, pero una soledad con un inmenso horizonte y una amplia luz difusa; la inmensidad sin más decorado que ella misma (...) Dicha inmensidad, Baudelaire acaba de decírnoslo en detalle, es una conquista de la intimidad. La grandeza progresa en el mundo a medida que la intimidad se profundiza. El ensueño de Baudelaire no se ha formado ante un universo contemplado (Bachelard 2000, 171-172).

Figura 2. Transformación de la intromisión y la inmensidad.
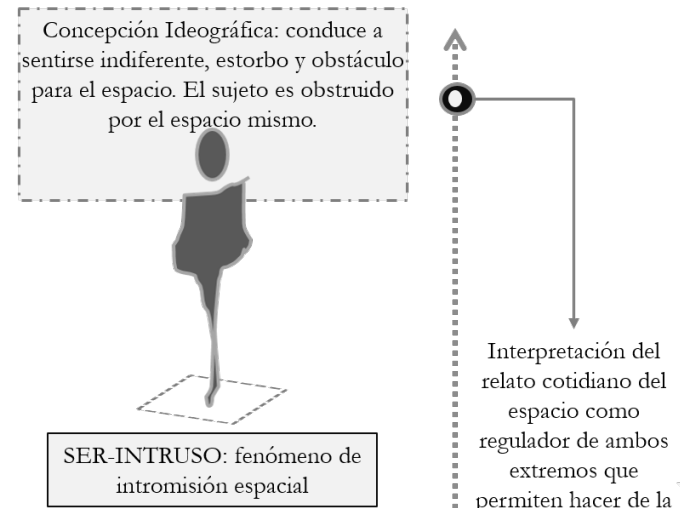

Interpretación del

relato cotidiano del

espacio como

regulador de ambos

extremos que

permiten hacer de la

intromisión y la

inmensidad, valores

positivos, al llevarlos

Concepción Ideográfica: conduce a

sentirse indiferente, perdido e 'insignificante para el espacio. El espacio' 'produce desinterés por parte del sujeto.i

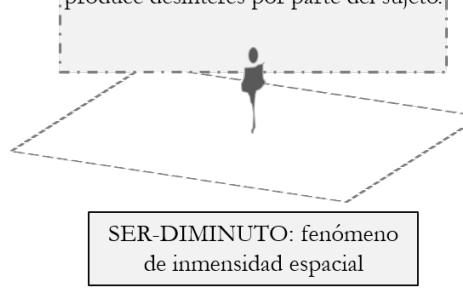

del espacio fisico, al

pacio ideográfico

del sujeto.
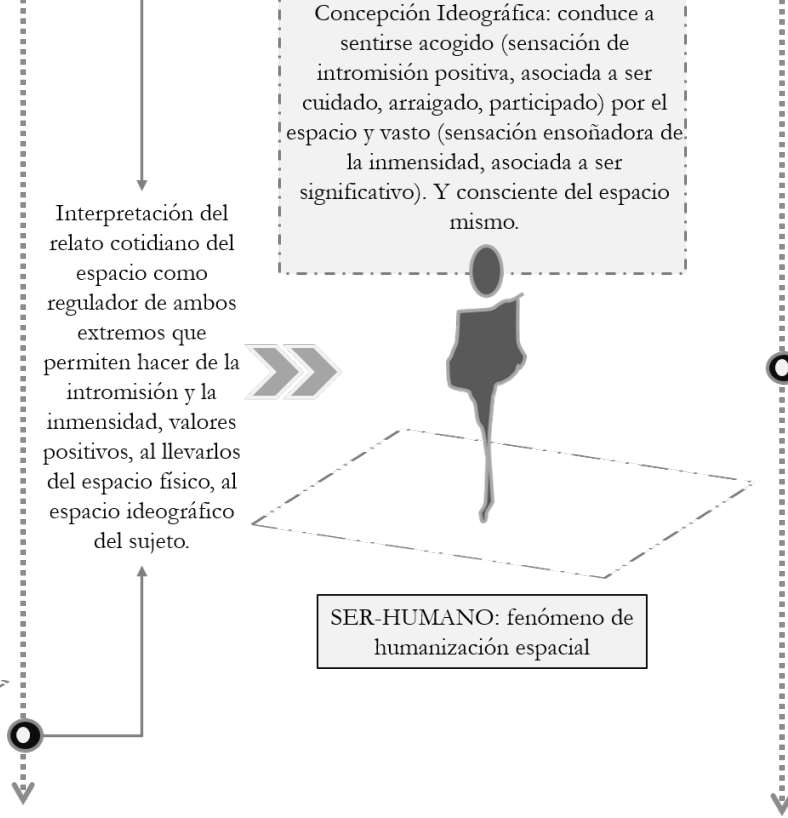

Adriana Masís Morales, 2018 
Entonces, se podría decir que nos encontramos en un proceso de hacer a un lado la indiferencia que nos invita a una restricción contemplativa, para más bien acercarnos a la humanización del espacio. Hemos llegado a una noción de que sentirse intruso del espacio, así como sentirse diminuto en medio de su enormidad, son valores que mantendrán un carácter mayormente negativo, mientras sean explorados, únicamente, en el medio físico, pues inducen a la indiferencia.

Ante la comunicación y la narratividad del espacio, que se traduce en conversaciones e ideas que surgen cotidianamente en todos los sujetos, sería posible llevar estos relatos a una interpretación que admita humanizar el espacio y llevar los valores de intromisión e inmensidad a la intimidad de nuestra concepción ideográfica. Esto significaría despertar la conciencia en el sujeto sobre ambos valores y trascender las descripciones planimétricas que nos distancian de construir e interpretar un relato; de cuyo significado, se desprende el espacio vivencial.

"El espacio íntimo así trabajado por el poeta [el arquitecto, creador, descubridor, interventor] no sería más el compañero del espacio exterior de los geómetras que, ellos también, quieren el espacio infinito sin más signo que el infinito mismo" (Bachelard 2000, 173). Este nuevo espacio no es inmenso ni diminuto en el sentido matemáticamente objetivo de un dimensionamiento infinito; es un espacio fenoménico, en el que estos valores son sentidos y no medidos. Por tanto, un espacio que nos hace sentir inmensos por dentro ('vastos' en el lenguaje baudelariano) y que se entromete positivamente (de manera acogedora) en el estado anímico y la concientización de los sujetos; sería asequible, de no ser por nuestra propia dificultad para reconocer la importancia de la fenomenología en la creación de un espacio.

Figura 3. Plano descriptivo de una fábrica china en la ciudad de Nagasaki, 1688

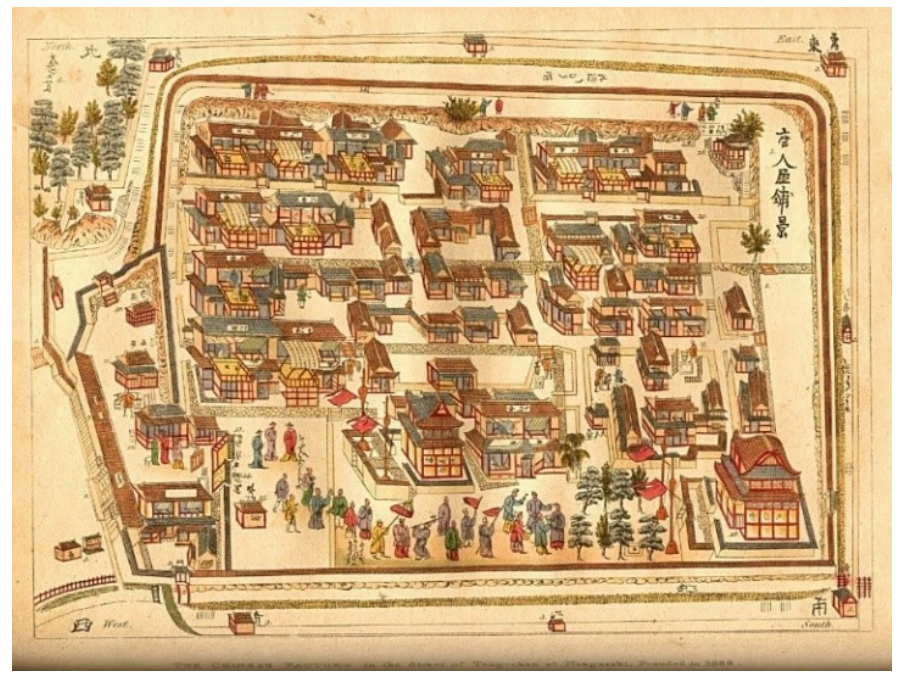

Recuperado de http://www.arquiscopio.com/pensamiento/espacio-/ugar-y-Arquitectura/ 


\section{Representaciones e influencias sobre la idea de espacio}

El espacio es descrito desde la planta, las secciones, elevaciones, o inclusive, las perspectivas más imposibles, pero en nuestro diario vivir es interpretado de formas tan personales y abstractas, que pedir un croquis o un plano a mano alzada de un mismo espacio a diferentes personas da por resultado visiones e ideas muy distintas entre sí. En ese aspecto, la arquitectura tiende a normar una serie de técnicas y de reglas simbólicas sobre la manera de expresar el espacio. Estas regulaciones surgen porque, de no conocerse el lenguaje técnico, el espacio se vuelve indefinible, incapaz de ser medido y difícilmente construido.

En todo caso, las técnicas gráficas ya están más que explicadas en los libros sobre dibujo técnico. Por su parte, los croquis, mapas o dibujos realizados sin estos conocimientos muestran una gran riqueza sobre la concepción ideográfica del espacio, en el sentido de que, en vez de profundizar en la frialdad de lo meramente técnico-constructivo, se sumergen en el mundo perceptual, relatan el espacio sin necesidad de juegos de geometría, sin un sentido de la escala más que las jerarquizaciones subjetivas que se generan en el recorrido del espacio.

El espacio es una ideación abordada de diferente forma, dependiendo de si se apunta a la física, al lenguaje técnico o a lo artístico. Por consiguiente, tendrá un significado distinto para un matemático, un físico, un arquitecto, un ingeniero, un topógrafo, un geógrafo, un pintor o un escultor. Sin embargo, en este caso, nos atañe su interpretación desde la vivencia del espacio, por eso, se podría hablar del espacio arquitectónico, la experiencia espacial o, a lo mucho, el espacio escultórico. Por ser un objeto que no contenga dentro de él a las personas que lo aprecian -como sí lo hace la arquitectura-, es, en parte, un acercamiento a lo que sería corporeizar el espacio.

Esta última aclaración tiene cabida porque, en ocasiones, se le trata a la arquitectura como una escultura, cuando en realidad, aunque ambas requieren un manejo del espacio, la arquitectura crea concavidades 'alrededor del' espacio y la escultura crea convexidades que 'están en' el espacio. Por supuesto, también nos encontramos con arquitecturas con ínfulas de escultura y con esculturas con presunciones de arquitectura, pero en este caso, la relevancia temática de ambos consiste en hacer notar que, para tratar la construcción ideográfica del espacio arquitectónico, tal espacio debe ser vivido de forma cotidiana y, para esto, debe ser apreciable por nuestros sentidos, tanto por dentro como por fuera, cóncavo y convexo simultáneamente.

La escultura es más un objeto en el espacio, que un espacio en sí, habitable de modo cotidiano. Tenemos la referencia de grandes esculturas por las cuales las personas pueden transitar o sentarse a conversar, pero no hacer una vida cotidiana. Sin embargo, la idea de un objeto que imaginariamente podemos recorrer y sentir es un ejercicio frecuente para concebir el espacio.

Tanto así, que se han elaborado relatos sobre ello. Por ejemplo, los que datan del siglo XVIII, como el del antiguo cuento tradicional inglés llamado, "Había una vez una anciana que vivía en un zapato" (There was an old wo- 
man who lived in a shoe) o la referencia oriental al genio que vivía dentro de una lámpara maravillosa, en las historias de Aladino, cuyo origen son "Las mil y una noches".

Figura 4. Proyecto Polly Pocket

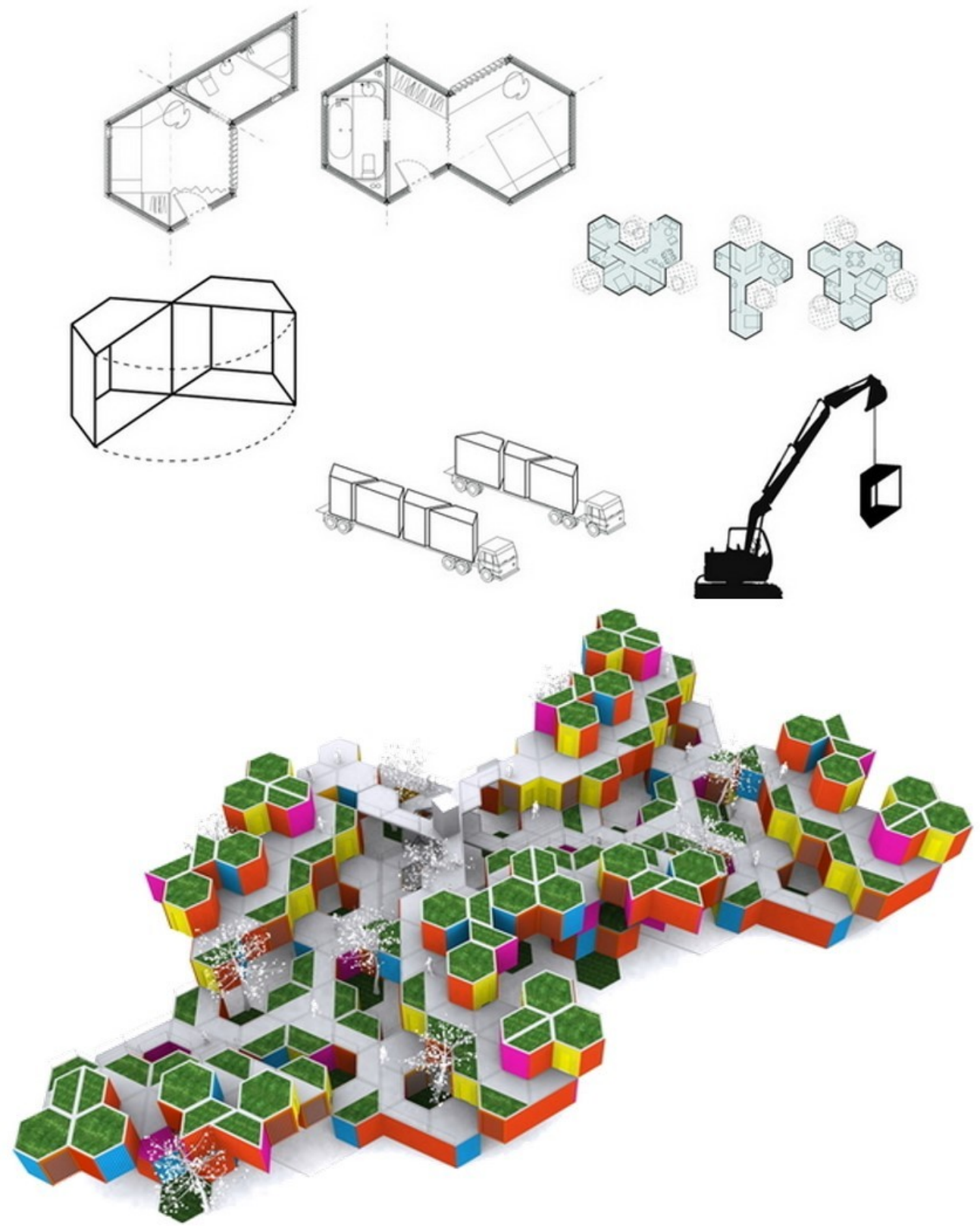

Recuperado de: http://ohlab.net/project/polly-pocket-2/ 
Otros ejemplos menos anticuados serían las pequeñas casas de muñecas y granjas de juguete que se despliegan con bisagras y a partir del siglo $\mathrm{XX}$, los juegos del tipo Polly Pocket, por medio de los cuales los niños desarrollan la habilidad de adentrarse en un espacio abundante dentro de la imaginación, pero que, como su nombre lo indica, se puede cargar en el bolsillo. Esto, además, inspiró un proyecto arquitectónico del mismo nombre de dicha marca de juguetes infantiles, en el cual se propuso alojamientos temporales transportables, viviendas de emergencia, e inclusive torres habitables bajo la misma idea de configurar espacios pequeños que se pudieran desplegar o modular para transformarse en otros más grandes.

Figura 5. Frank Lloyd Wright, Hilla Rebay y Solomon Guggenheim, con la maqueta del Museo Guggenheim en 1945

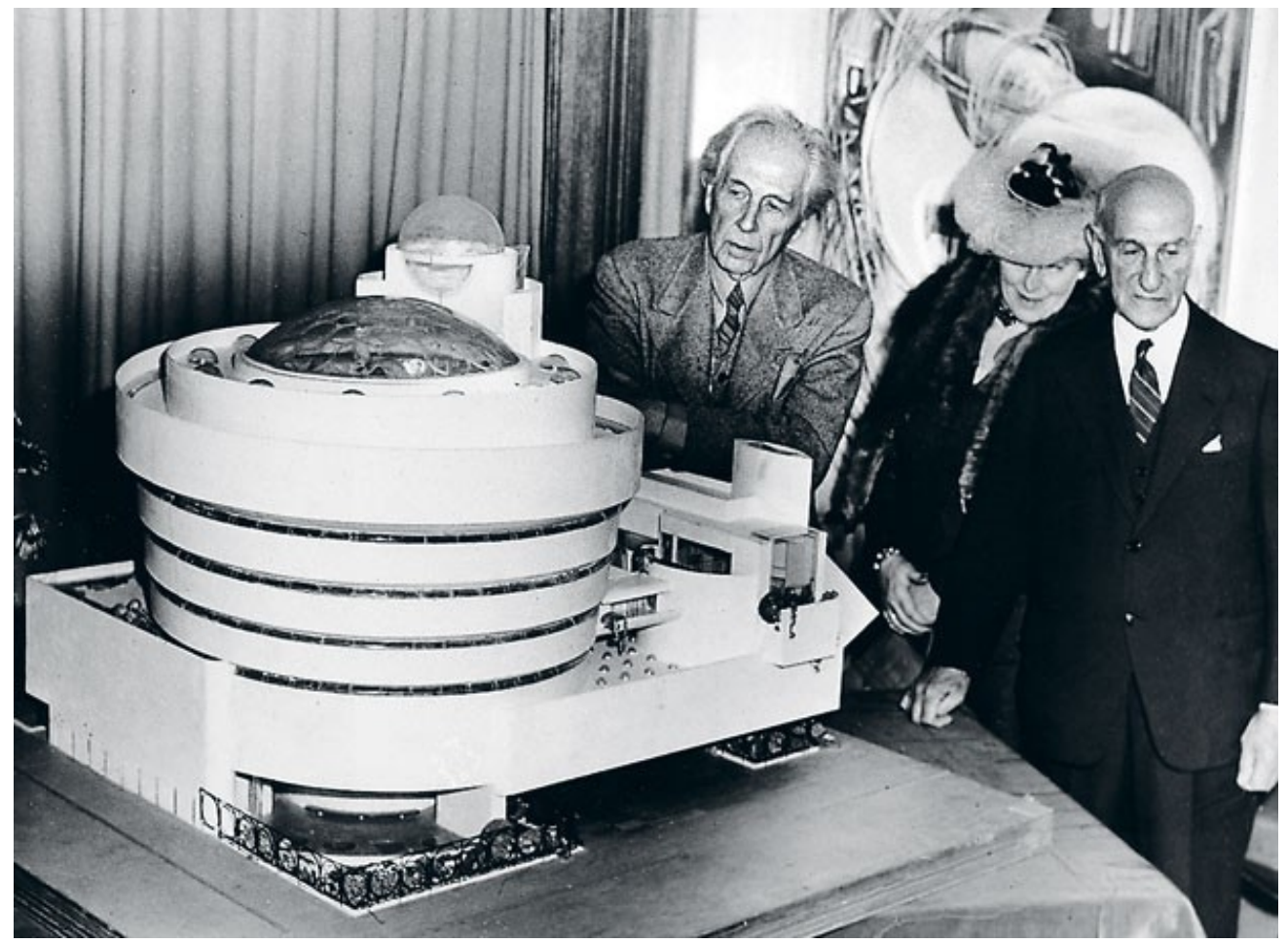

Recuperado de http://elpais.com/diario/2009/10/11/eps/1255242410_740215.htm/

Estos ejercicios imaginativos que se narran en los cuentos y en los juegos infantiles son también explotados por los arquitectos para entender, componer y estudiar el espacio. Por ejemplo, cuando se construye una maqueta, no se hace regularmente en la escala real, sino que se aprovecha la herramienta del modelo como un acercamiento a las relaciones entre espacios, la luz, aspectos bioclimáticos y demás conceptualizaciones; por lo tanto, esta habilidad de inducirnos dentro del espacio resulta esencial para construir la imagen mental de los potenciales atributos por explotar, en intervenciones pro- 
yectuales que aún no van más allá de un objeto extraño que se posa sobre una mesa de dibujo.

Si nos colocamos en una perspectiva filosófica, tenemos que Aristóteles habla del espacio entendido como un recinto o envolvente con cualidades específicas que abriga cuerpos capaces de emplazarse y de desplazarse en él, lo que se podría llamar un lugar o topos, donde "la palabra tópos implica la presencia de un ser animado limitado por eschata (límites)" (Arisó 2012). Por esto, el espacio se definiría como una consecuencia del sujeto o ser animado que al verse contenido en una configuración espacial, logra reconocerse dentro del espacio.

Por otra parte, Newton trata el espacio en un sentido matemático, como un contenedor universal en el que se encuentran todos los objetos, tanto los animados como los inanimados. Así Newton afirma:

Por las posiciones y distancias de las cosas a un cierto cuerpo que consideramos inmóvil, definimos todos los lugares; posteriormente interpretamos todos los movimientos por respecto a los antedichos lugares, en tanto que los concebimos como pasos de los cuerpos por estos lugares (Ochoa, 2000).

Newton considera que nos damos cuenta del movimiento de los cuerpos al referenciarlos con algo que no se mueve; lo que sería el espacio absoluto, el cual se encuentra en reposo como una referencia inmóvil.

Por último, Einstein retoma todo lo anterior, pero le suma la variable temporal, y llega a un concepto cuatridimensional del espacio. Esto, además, significó la transformación del espacio en algo relativo, pues al pensar el espacio en términos de su percepción en el transcurso del tiempo, resulta que no es necesariamente inmóvil y es una idea abstracta.

En la física relativista, el espacio y el tiempo quedaron ligados indisolublemente. No existe el uno sin el otro. La relatividad del tiempo y del espacio significa que tanto uno como el otro dependen del observador. Esto quiere decir que los valores numéricos asignados a mediciones de tiempo y espacio, por diferentes observadores para los mismos fenómenos, son distintos. La relación entre ellos depende de las velocidades relativas entre ambos observadores (Morones Ibarra, 2004). El espacio al llevar consigo una variable temporal, la arquitectura sería una evidencia del paso del tiempo en el espacio, en el cual se envuelven las vivencias que, finalmente, inspiran a escritores, narradores y poetas a construir sus versiones del espacio como relato de la realidad cotidiana. 
Figura 6. Evolución de la Idea de Espacio

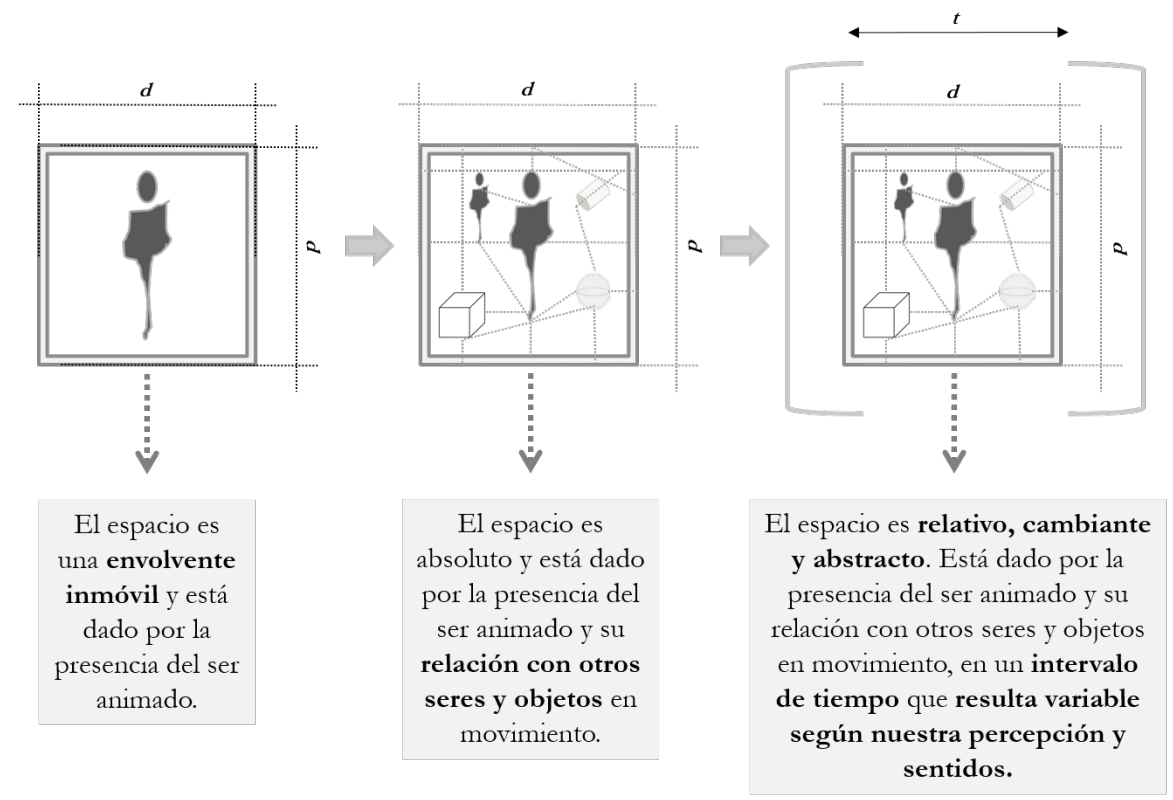

Adriana Masís Morales 2018.

Esos aportes científicos, en definitiva, afectaron el sentido del espacio para la arquitectura, pues comprueban que se trata de un asunto que va mucho más allá de una medición o un contenedor, sino que es afectado por el paso del tiempo y por la percepción del sujeto. Algunos filósofos, además, aportan enriquecedoras especulaciones que se acercan a los aspectos sensibles del espacio.

Heidegger, por ejemplo, nos conduce a interpretar la idea de espacio desde otra cultura: la alemana. Al brincar la barrera idiomática, vemos que, en su obra El arte y el espacio (Die Kunst un der Raum), equivocadamente se dice que raum es lo mismo que espacio, cuando en realidad, "en alemán, el término raum tiene el sentido de fragmento de la totalidad de los espacios, cuyos límites visuales son fronteras que acotan unas distancias" (Maderuelo 2008, p. 14). Esta distinción es clave porque en ella explica que estas fronteras son reconocibles porque han sido nombradas y el que les ha dado nombre es el sujeto. Bajo esta visión, el sujeto existe al dar lugar al raum en el espacio, es un mediador, por medio del cual su propia existencia y la del espacio, adquieren sentido.

Dentro de la abstracción infinita que científicamente llaman espacio, el sujeto configura otro más pequeño, al cual se le conoce como fragmento espacial o raum, en el cual queda contenido el sujeto y un fragmento de la inmensidad del espacio, el cual, además de una ubicación topográfica, tiene una variable temporal. Y de todo aquello, finalmente, en arquitectura, le llamamos a un espacio con carácter de lugar al fenómeno por medio del cual el espacio es, de forma genuina, pensado (interpretado, sentido, transformado, interiorizado, 
etc.), o sea, hecho consciente por el sujeto quien, al darle el ser al espacio, crea su propia existencia.

Figura 7. El Lugar en el Espacio

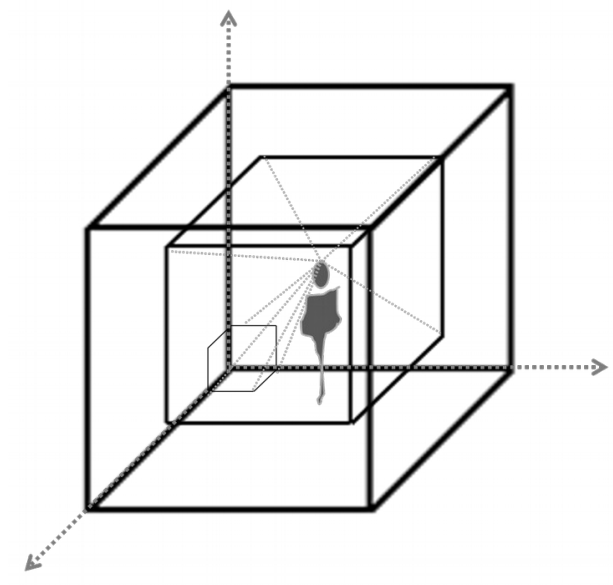

Adriana Masís Morales 2018.

Al llegar a esta figuración, queda entredicho que el sujeto tiene una vocación de encontrar su lugar en el espacio, por eso, en una entrevista, Jacques Derrida confirma:

La cuestión de la arquitectura es de hecho el problema del lugar, de tener lugar en el espacio. El establecimiento de un lugar que, hasta entonces, no había existido y que está de acuerdo con lo que sucederá allí un día: eso es un lugar. En absoluto es natural. El establecimiento de un lugar habitable es un acontecimiento. $Y$ tal establecimiento supone siempre algo técnico (Gardinetti, 1986).

Esta condición humanizante, por medio de la cual las personas dan vida (crean) a su lugar en el espacio y perciben acontecimientos, a saber: el encierro y la amplitud o la pequeñez y el gigantismo, entre tantas otras cualidades que el espacio pudiera tener. Es un enriquecedor matiz que pone en pie la intrincada relación espacio-tiempo-sujeto, como una de las más importantes en el diario vivir y que afecta nuestro ser-en-el-mundo.

Tal condición va mucho más lejos que las mediciones, las direcciones y los puntos cardinales que definen una ubicación espacial, pues eso sería materia de la ingeniería o de la topografía. No es ubicar elementos de la naturaleza, ríos, montañas y accidentes naturales en general, pues eso corresponde a la 
Geología. Tampoco, los papeles culturales, según su posición geográfica, pues eso pertenece más a la Antropología y a la Historia.

En definitiva, cada disciplina aporta un sentido al espacio, pero de todas ellas, la Filosofía y la Arquitectura tienden a ahondar más en los fenómenos del espacio, que son menos concretos y evidentes. El espacio es afectado por nuestra condición humana, por medio de la cual le atribuimos sentido, ya que nos apropiamos de él cambiando su aspecto físico, y tanto cultural como personalmente, somos capaces de crear un sentido de pertenencia en torno a él, debido a nuestras afecciones emotivas.

Resulta curioso en qué medida si los seres humanos nos apropiamos del espacio acorde a nuestros propios intereses y afinidades, igualmente, los espacios que creamos no nos pertenecen, sino que acabamos perteneciendo a ellos, debido a su influencia sobre nuestro actuar y sentir. De forma que, por haber nacido en Rusia, no seríamos los mismos que de haber nacido en $\mathrm{Na}$ mibia o Canadá; y eso sin ahondar aún más en los pueblos, barrios y vecindades que configuran el espacio y que necesariamente afectan a los sujetos que viven en ellos.

Sin ir tan lejos, el hecho de habitar en una casa o en otra cambia nuestros hábitos, modo de actuar y las sensaciones respecto al mundo, de modo que, aunque innegablemente existe un gran peso en la geografía y cultura, los espacios creados por el ser humano para otros seres humanos, desde la Arquitectura, son un detonante de la forma en que habitamos el mundo, pues tanto afectamos nosotros el espacio como el espacio a nosotros.

\section{Conclusión. Todo lugar es un espacio, pero no todo espacio es un lugar.}

Podemos inferir que, al estar la arquitectura tan arraigada a las percepciones culturales, si se discute de la creación de un espacio; se habla, además, de la construcción de emociones, de realidades y de posibles nuevos significados que se sumarán al imaginario colectivo de la sociedad. Muntañola restringe la idea de lugar a los contenidos en esencia, observables y fácilmente reconocibles cuando señala:

El lugar es una envolvente lógica en tanto contenga un orden racional. Es ético en cuanto debe abrigar los usos tanto de los unos como de los otros. Y, finalmente, es una envoltura estética en cuanto remite a un más allá imaginario. 
(...) el lugar es distinto de su contenido; pero está, no obstante, en resonancia con él, puesto que lo agrupa y exterioriza la forma con que lo agrupa, todo al mismo tiempo" (Muntañola Thornberg, 2009).

Si bien es cierto, Muntañola describe valores indiscutibles del espacio, como una envolvente lógica, ética y estética, quedaría aún pendiente reconocer su carácter ideográfico simbólico.

También, el espacio construye, de modo ideográfico, aquellos espacios que ignora. Esto quiere decir que el no-lugar forma parte del fenómeno del espacio. En un mundo que se "desarrolla" tan aceleradamente, se podría decir que nunca hubo tantos no-lugares como los hay en estos tiempos:

(...) los no lugares son la medida de la época, medida cuantificable y que se podría tomar adicionando, después de hacer algunas conversiones entre superficie, volumen y distancia, las vías aéreas, ferroviarias, las autopistas y los habitáculos móviles llamados "medios de transporte" (aviones, trenes, automóviles), los aeropuertos y las estaciones ferroviarias, las estaciones aeroespaciales, las grandes cadenas hoteleras, los parques de recreo, los supermercados, la madeja compleja, en fin, de las redes de cables o sin hilos que movilizan el espacio extraterrestre a los fines de una comunicación tan extraña que a menudo no pone en contacto al individuo más que con otra imagen de sí mismo (Augé 2000, 84-85).

Los no lugares se caracterizan por ser espacios estancados, con tanto movimiento que se sienten sin vida en medio del tránsito ininterrumpido de personas o con ningún movimiento en absoluto, negados a participar de la vida en sociedad y de las actividades del diario vivir. Pero, para su ventaja, son también los espacios en los que ocurre un conjunto de itinerarios azarosos y que representan un nicho de infinitas posibilidades experimentales.

Clásicamente, los vemos representados en un parque, una parada de bus, un área intersticial entre grandes edificios, áreas de descanso o los alrededores de autopistas, entre tantos otros. En realidad, están por todas partes, pero no los notamos por su condición de no-lugares. Son espacios destinados al aislamiento, como el pasillo de un hospital o el de una torre habitacional, donde perfectamente podemos ir y venir de nuestros quehaceres, sin ha- 
cer ningún intercambio con el entorno. No tienen identidad, no tienen un relato que contar y, por lo general, no son memorables. Se sienten tan lúgubres como una escuela sin niños y tan inclementes como caminar en medio de un aeropuerto.

Dichos espacios son ideográficamente inexplicables, debido a que no tienen una configuración clara dentro de los mapas mentales del sujeto. Y al igual que en el caso del tiempo -que es cada vez más difícil de explicar históricamente a raíz de la alta profusión de acontecimientos en el mundo-, este es también víctima de los fenómenos de nuestra época, que tienden al individualismo, al cambio constante y a la carencia de construcciones identitarias del entorno. Por eso, se establece este paralelismo espacio-temporal, sobre el cual la posmodernidad compone uno de los principales factores de cambio, según:

$$
\text { (...) así como la inteligencia del tiempo —creímos- se }
$$

complica más por la superabundancia de acontecimientos del presente de lo que resulta socavada por una subversión radical de los modos prevalecientes de la interpretación histórica, del mismo modo, la inteligencia del espacio la subvierten menos los trastornos en curso (pues existen todavía terruños y territorios, en la realidad de los hechos de terreno y, más aún, en la de las conciencias y la imaginación, individuales y colectivas) de lo que la complica la superabundancia espacial del presente. Esta concepción del espacio se expresa, como hemos visto, en los cambios en escala, en la multiplicación de las referencias imaginadas e imaginarias y en la espectacular aceleración de los medios de transporte y conduce concretamente a modificaciones físicas considerables: concentraciones urbanas, traslados de poblaciones y multiplicación de lo que llamaríamos los "no lugares" (...) (Augé 2000, 40).

Se trata, en pocas palabras, de los espacios sin evento. Recordemos que sin evento, no hay relato, y sin relato, no hay sentido de lugar. De este modo la tertulia en la banca de una plaza, el saludo del pulpero que en la mañana desde el quicio de la puerta recibe a sus proveedores o el intercambio de miradas con la señora que sale por las tardes a regar su jardín son indicios del evento y son, al menos, hechos reconocibles que marcan tiempos del día y espacios del recorrido. Sin embargo, si esa banca del parque está en un lu- 
gar peligroso, el quicio de esa puerta es angosto e incómodo y las aceras son tan difíciles de transitar que no hay oportunidad de observar a la señora que riega el jardín, tampoco será posible concebir estos espacios como lugares.

Algunos se mantienen, y otros, como la pulpería, se encuentran en vías de extinción. Si bien este lugar podría despertar la nostalgia de quienes añoran los frascos con golosinas artesanales, pedir "feria", regatear precios, comprar comestibles de fiado o la tradicional cantina oculta dentro de la pulpería tras una cortina hecha con abalorios colgantes de madera; haciendo un punto y aparte sobre los muchos recuerdos referentes a este espacio, lo que en realidad lo caracteriza como lugar es superior a esa entrañabilidad.

Figura 8. Jorge Araya. Un lugar: pulpería de Emilio Pochet en Alajuela, óleo sobre tela, 2009 (Certamen Nacional de Pintura, Homenaje a la Pulpería)

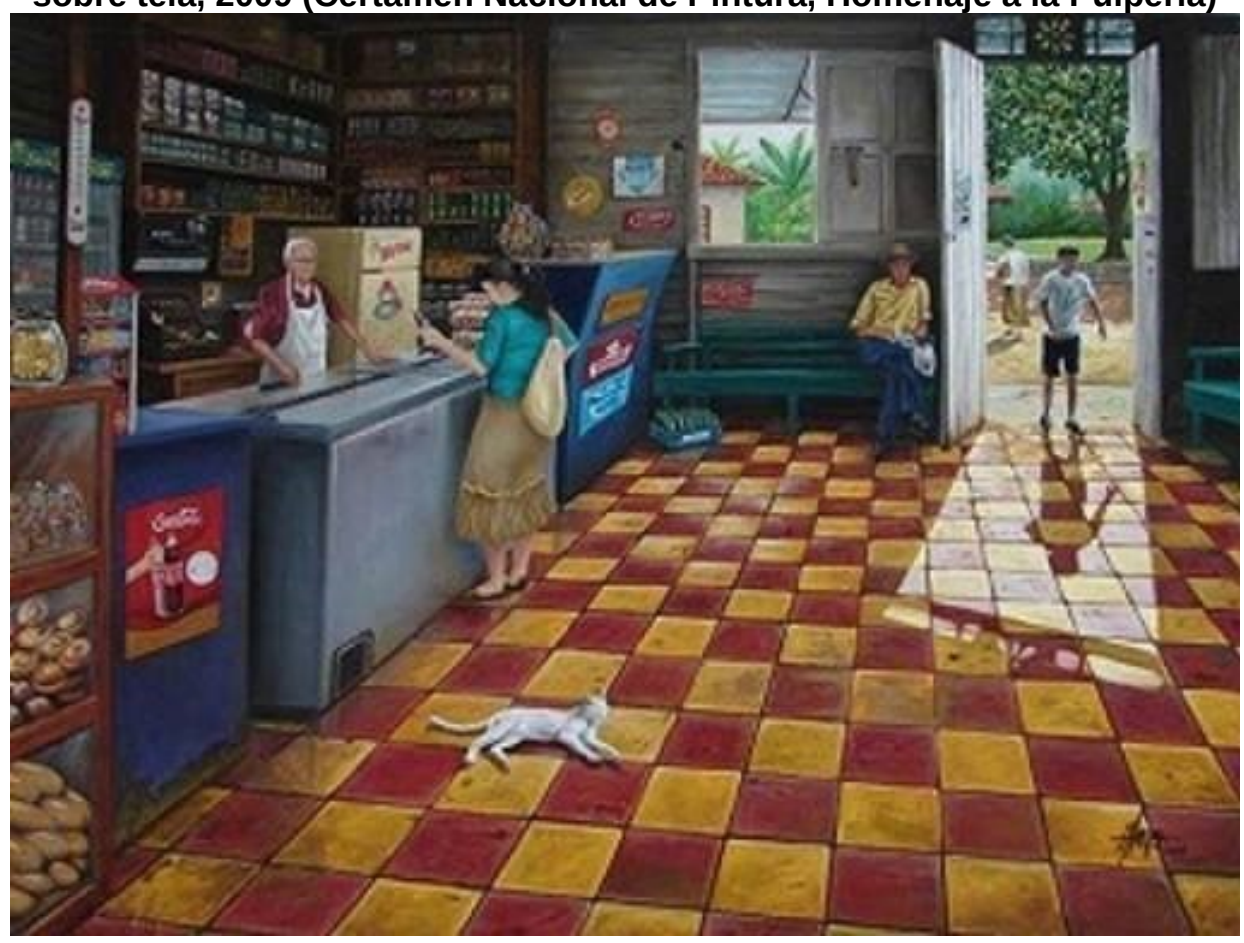

Recuperado de http://www.ticoc/ub.com/mudelni/lapul001.jpg

Este, igual que otros, es lugar porque es un emblemático punto de encuentro, visitado, con frecuencia, por personas de todas las edades. Un lugar que, a pesar de la amenazadora presencia de los grandes supermercados impersonales, no desaparece porque es poseedor de un evento más relevante inclusive que la compra del encargo; la práctica significante de convivir. Al respecto, en un artículo sobre la imagen semiótica de este tipo de actividades significantes, Fernández y Rojas (2000) comentan: 
La pulpería -simple objeto sígnico, pero a su vez objeto designado, referente a través de la voz del interpretantecomo sitio de ventas, de comunicación, información y centro de tertulia, ha constituido y constituye una práctica social y como tal, un espacio de relaciones sociales y humanas, un lugar de vital importancia y necesidad para todos los vecinos, un centro en torno al cual gira muchas veces, la vida del barrio (Fernández Carballo y Rojas Carranza, 2000).

Finalmente, esto lo convierte en punto de referencia para dar direcciones, puesto de vigilancia permanente para el barrio, una fuente de empleo familiar que no se acoge a las estipulaciones de los grandes almacenes, un espacio para anunciar actividades comunales, como partidos, misas, reuniones de comités vecinales o artículos en venta; es decir, un área para conversar, discutir asuntos deportivos, políticos y hasta filosóficos.

Es un objeto cultural y, por ende, objeto semiótico, portador de contenidos y generador de mil significados (...) que va más allá de la simple función comercial a pequeña escala, que se convierte en sinónimo de la identidad costarricense, en el sentido de pertenencia a la cultura nacional (Fernández Carballo y Rojas Carranza, 2000).

Se trata de uno de los más claros ejemplos de rebeldía espacial, pues compitiendo con espacios que parecen ofrecer un ambiente pulcramente organizado, de autoservicio y de amplios pasillos, se ofrece su lugar en medio de productos sin precio y un aspecto saturadamente barroco, como un estandarte del espacio sin monopolio y en el cual queda demostrado que no, únicamente con el aporte teórico y práctico de los arquitectos se construye el espacio, sino también que es una construcción en conjunto; de todos los sujetos.

Sin embargo, tras la marginación que han recibido, en muchas ocasiones, las arquitecturas espontáneas, se nos ha dificultado aprender a leer y a estudiar el imaginario colectivo, valorar los emprendimientos informales que revelan necesidades reales, así como crear procesos que traduzcan los relatos vivenciales en espacios habitables. A razón de esto, se promueve la crisis de los lugares y la invasión de los no-lugares, que traería, por consecuencia, una vertiginosa dispersión del espacio, el ordenamiento forzoso y la mal comprensión de los itinerarios en el recorrido que, en muchos casos, dificultan la creación de caminos o sendas informales. 


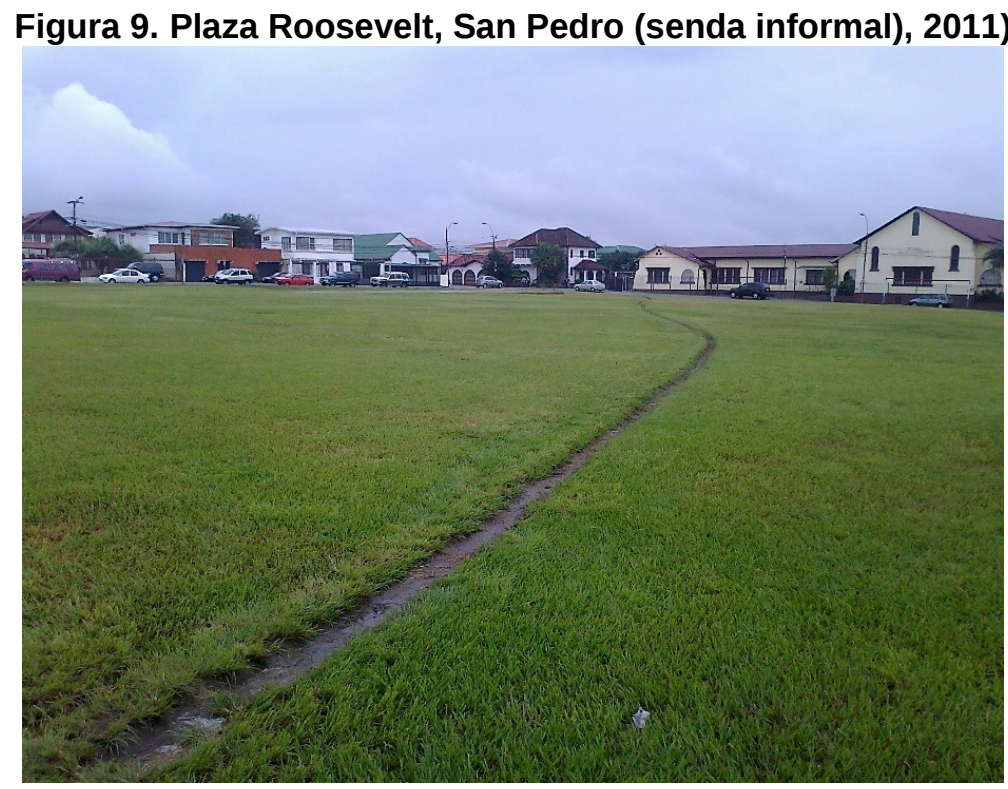

Adriana Masís Morales 2018.

En los no-lugares, se tiende a manifestar una programación excesiva, que tergiversa la riqueza de nuestros modos singulares de habitar, de cocrear y de convivir, de modo que el sujeto aprende a confortarse en un espacio hiperplanificado, para que no haga contacto con sus vecinos, que no puedan ver los jardines, porque hay murallas que los protegen $\mathrm{y}$, preferiblemente, para que no camine, porque el gran predilecto, de entre todos los medios de transporte. es el vehículo, cuyas consecuentes calles asfaltadas son la envidia de todas las aceras ahuecadas, desniveladas y con obstáculos. Esta impersonalización del espacio es comercializada con el disfraz de la comodidad, traída a nuestras vidas como un privilegio que, en su paso destruye el concepto de comunidad, la idea de convivencia y el disfrute del recorrido. Un impetuoso anuncio publicitario lo explica a continuación: "Un día, la necesidad de espacio se hace sentir... Nos asalta de repente. Después, ya no nos abandona. El irresistible deseo de tener un espacio propio. Un espacio móvil que nos llevara lejos. Nada haría falta; todo estaría a mano..." En una palabra, como en el avión. "El espacio ya está en usted... Nunca se ha estado tan bien sobre la Tierra como en el Espacio", concluía graciosamente el anuncio publicitario (Augé 2000, 12).

A pesar de ello, en ocasiones, puede suceder que, de manera organizada, se realice un evento en un no-lugar; sin embargo, debe ser algo estrictamente planificado para que pueda suceder y que, de otra forma, no se repetiría con frecuencia, seguirá siendo un testimonio de ausencia de identidad.

Fuera de estos intentos, es curioso, como en nuestros tiempos, también la tecnología comienza a mediar el no-lugar. Tras el ejercicio de observar a las personas y a los conductores vecinos, en medio de un apiñamiento vehicular, 
es impresionante verlos recorrer sus obligadas horas tras el volante en la autopista-no-lugar; conversando con amigos mediante sus manos libres; comunicándose con familiares a través de videollamadas que se reflejan en las pantallas de sus automóviles; navegando por internet o disfrutando de alguna canción.

Ellos, en completa soledad, a veces niegan ser vistos - a través de ventanas polarizadas - y evitan el contacto visual con otros conductores para no verse comprometidos a ceder espacio en la competitiva jungla de asfalto. También, están compartiendo e informándole a alguien 'por dónde van' y, en ocasiones, hasta emprenden un viaje mental a través del relato de otro conductor que se encuentra manejando en zonas menos saturadas y hostiles; narrando -lugares- que empapan al conductor citadino con vivencias más agradables.

¿Significa esto que el no-lugar puede aspirar a convertirse al menos en un espacio comunicacional? Ciertamente, las horas de camino en medio de un embotellamiento pueden ser suficientes para ahondar en relatos que nos transporten a un viaje fuera del viaje, comentando experiencias y recuerdos; imágenes nubladas de lugares mitad imaginados y mitad recordados, como escenas mentales que se despliegan ante los ojos de quien habla y de quien escucha, cada uno creándose su propia idea. Sin embargo, el hecho de tener que nombrar estas experiencias en tiempo pasado y, en especial, aludiendo a otros lugares, aleja la posibilidad de construir un hecho significativo propio del no-lugar. Simplemente, son relatos prestados para compensar el paso por el no-lugar, como un consuelo de saber que existen espacios de mejor calidad que sí resguardan nuestro sentido de humanidad

Tales relatos no pueden implantarse (o no deberían implantarse) materialmente, porque cuando lo hacen, más bien incrementan la falta de contenido y de carácter de no-lugar. Traducirlos en ideas más tangibles que el relato mismo conduciría a la creación de proyectos alegóricos absurdos, como ya sabemos que sucede en Las Vegas, por ejemplo, donde las culturas, modos de vida, construcciones arquitectónicas de lugares y épocas pasadas han terminado transformadas en espectáculo banal, cosificando momentos espaciotemporales que fueron realmente vividos en esencia, por otros sujetos.

Así, tomar prestado otro tiempo y otro lugar podría implicar una insensibilización, ya que habrá sujetos que sientan esto como una burla a su cultura y a su historia. Ellos que conviven o convivieron en 'eso', que ahora se construye como una réplica ordinaria de la Torre Eiffel o el Gran Canal de Venecia (por mencionar algunos), y observan el paso de un relato significativo a una burda narración comercial, de repente, transitan en medio un duplicado vulgar y se convierten en:

Espectadores de sí mismos, turistas de lo íntimo, no podrían imputar a la nostalgia o a las fantasías de la memoria los cambios de los que da testimonio objetivamente el 
espacio en el cual continúan viviendo y que no es más el espacio en el que vivían (Augé 2000, 61).

Por otra parte, y una vez dichos los aspectos negativos del no-lugar, desde la perspectiva de Augé, lo positivo de estos espacios es que son los espacios de la sorpresa que, por el hecho de carecer de identidad, son capaces de asumir todas las identidades o ninguna, cualquier día y en cualquier momento. Por eso pregunta:

¿Acaso hoy en los lugares superpoblados no era donde se cruzaban, ignorándose, miles de itinerarios individuales en los que subsistía algo del incierto encanto de los solares, de los terrenos baldíos y de las obras en construcción, de los andenes y de las salas de espera en donde los pasos se pierden, el encanto de todos los lugares de la casualidad y del encuentro en donde se puede experimentar furtivamente la posibilidad sostenida de la aventura, el sentimiento de que no queda más que "ver venir"? (Augé 2000, 10-11)

Debido a que se trata del espacio que todavía no es lugar, el evento puede ser cualquier evento, todo puede suceder (aunque eso también significa que puede suceder: 'nada'). Augé, al menos, apunta a llevar el no-lugar a ser vivido sin tanta indiferencia, más bien como algo que se puede transformar, cultural y arquitectónicamente, en una amena transición entre espacios o un elaborado trayecto que se reinventa de forma constante y nos narra el espacio sentido como distancia entre un punto y otro. Básicamente, es el no-lugar, visto como el espaciamiento entre espacios, pero un espaciamiento que no resulta ajeno al sujeto, considerando que si se deja de plantear como meramente funcional, podría acceder a la memoria colectiva y, así, cobrar sentido.

En todo caso, lugar y no-lugar; ambos son ideografías de espacio que tienen un carácter confrontativo, pero no son exactamente palabras antónimas. Un lugar bajo condiciones distintas en su configuración, época, uso y demás aspectos condicionantes, será tal vez recordado, pero podría convertirse en nolugar. Igualmente, el no-lugar no lo es por completo ni necesariamente para siempre, pues tiene en su existencia la posibilidad de encontrar una identidad:

El lugar y el no lugar son más bien polaridades falsas: el primero no queda nunca completamente borrado y el se- 
gundo no se cumple nunca totalmente: son palimpsestos donde se reinscribe sin cesar el juego intrincado de la identidad y de la relación (Augé 2000, 84).

Figura 10. Bernard Tschumi Architects, Advertisements for Architecture, 1976-1977*

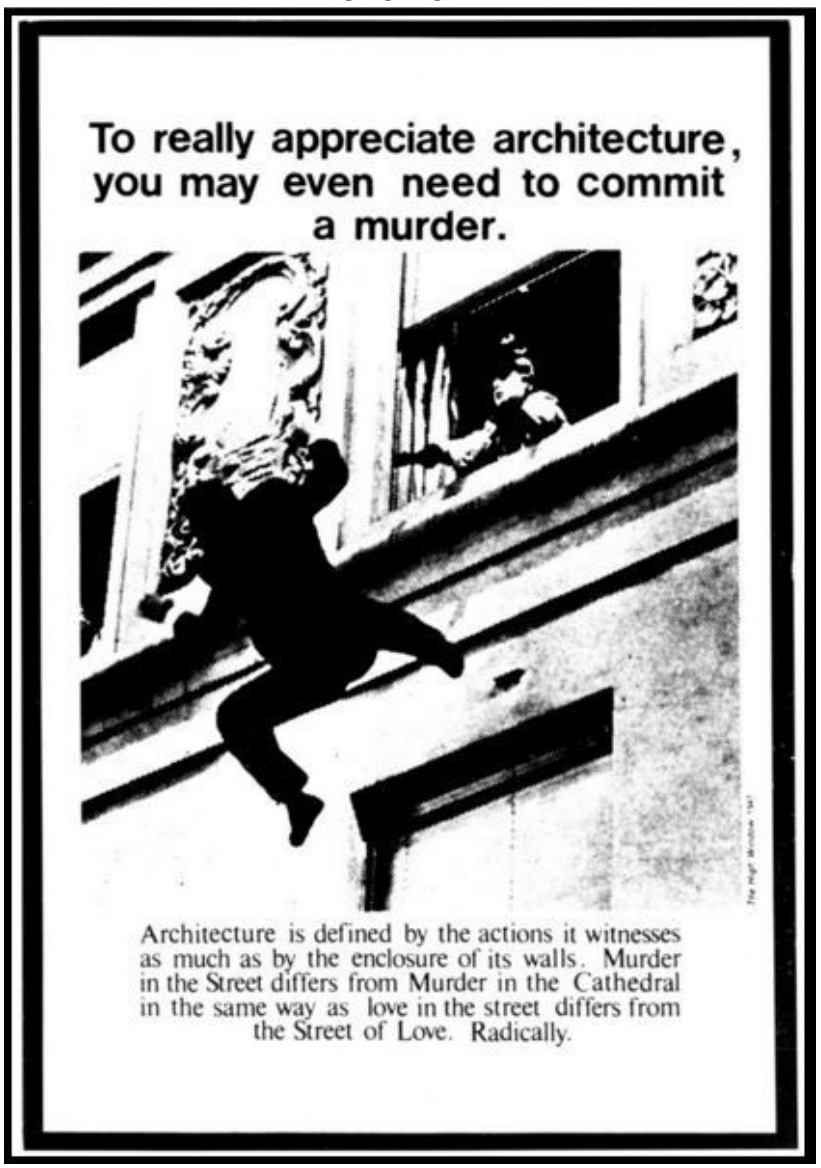

*Bernard Tschumi Architects, publicidad para arquitectura, 1976-1977 (el texto en español indica: para realmente apreciar la arquitectura, podrías incluso necesitar cometer un asesinato. La arquitectura está definida por las acciones que atestigua, tanto como por el cercamiento de sus paredes. El asesinato en la calle difiere del asesinato en la Catedral, así como el amor en la calle, difiere, radicalmente, de la Calle del Amor)

Recuperado de: http://www.tschumi.com/media/files/00223.jpg

Ideográficamente, el espacio como vivencia tiene lugar en algún punto entre las humanidades, las ciencias, la filosofía y las artes; por lo tanto, desde un principio, posee una condición interdisciplinaria. Llamar palimpsestos a los lugares y no-lugares es una forma audaz de reconocer la posibilidad de escribir y de sobrescribir un nuevo texto que reconfigure la concepción ideográfica. 
Lo que particularmente afecta la posibilidad de llevar esta reconfiguración a cabo es el entendimiento de los espacios como fragmentos del tiempo y fenómenos metafísicos marcados a través del evento. Un relato unifica ambas cosas, tiene un espacio y un tiempo, narra el evento y reivindica el valor simbólico de ese instante temporal y ese fragmento espacial. Por tal motivo, lo ideográfico se construye, en su mayoría, en la visión del espacio como texto complejo que suscita eventos y se crea su nicho en el mapa mental de los sujetos. Evidentemente, esto no significa que el relato pueda 'ser la arquitectura' como tal, pero sí un momento previo que le confiere la posibilidad de una interpretación, que refleje y recree nuevos espacios vivenciales. De esta forma, un grupo de espacios, que parecen no tener relación alguna, está construido en un relato vivencial que, para otros sujetos, pueden tener un sentido lógico, emotivo o sensorial. Esto porque "Antes de conocer siquiera la palabra Arquitectura, todos nosotros ya la hemos vivido" (Zumthor 2004, 55).

En efecto, este acercamiento al asunto ideográfico como complemento para acercarnos a la exploración de valores intangibles, por un lado, podría estar cerca del concepto de atmósfera que utiliza Zumthor. Por otra parte, la atmósfera, así como se le describe en el análisis de obras literarias, es una noción del escenario o lugar en el que transcurren los hechos, sumado a los sentimientos y sensaciones intrínsecos de ese lugar; es como una descripción de la emotividad del lugar que construye figurativamente su propio ambiente o clima emocional.

Zumthor lo explica a través de la creación de un relato sobre una plaza, sobre la que va citando ideas enlazadas y otras aisladas que terminan por mostrar que la atmósfera de un espacio lleva implícitas muchas variables, permanentes y cambiantes, agentes externos y cosas que solo son destacables para el propio observador. Luego, trata de mantener estas emociones sin mirar hacia la plaza y descubre que se han desvanecido; lo que quiere decir que el espacio tiene un gran poder para estimular nuestro estado anímico, pensamientos y expectativas. Por eso concluye: "Nunca hubiera tenido tales sentimientos sin esa atmósfera de la plaza. Lógico. Hay un intercambio entre las personas y las cosas. Con esto tengo que tratar como arquitecto. $Y$ pienso: esta es mi pasión" (Zumthor 2006, 17-18).

Entonces, tratándose de un intercambio, si bien con la mirada tocamos el espacio, también debemos admitir que esa imagen de la que nos impregnamos puede tocarnos. Esto tiene una participación activa sobre nuestra concepción ideográfica del espacio, es capaz de romper la sensación de no-lugar, al tiempo que revitaliza las posibilidades de crear, generar apropiarse y organizar comunidades para atender nuevas oportunidades de transformación y de regeneración del barrio y la ciudad. 


\section{Bibliografía}

Arisó Cruz, Albert. 2012. «La Noción de Lugar en la Física Aristotélica». Revista de Filosofía Thémata 45: 35-50

Augé, Marc. 1996 Los «No Lugares» Espacios del Anonimato: Una antropología de la Sobremodernidad. Barcelona: Editorial Gedisa, 2000.

Bachelard, Gaston. 1957. La Poética del Espacio. Buenos Aires: Ed. Fondo de Cultura Económica. 2000.

Destutt de Tracy, Antoine Louis Caude. 1830. Elementos de Ideología. Caracas: Valentín Espinal. 1915.

Eisenman, Peter. 1995. «El "Zeitgeist" y el Problema de La Inmanencia». Monografías AV, 53: 27-33

Fernández Carballo, Rodolfo y Vilmar Rojas Carranza. 2000. «La pulpería: Imagen Semiótica de una Práctica Significante en la Historia Económica y Social de Costa Rica». Revista InterSedes 1(1): 93-105. Acceso el 8 de julio de 2016. http://www.redalyc.org/articulo.oa? $\underline{\mathrm{id}=66610110}$

Gardinetti, Marcelo. 2014 «El pensamiento arquitectónico por Jacques Dérrida». Revista Tecnne. Acceso el 8 de julio de 2016. http://tecnne.com/biblioteca/publicaciones/el-pensamiento-

arquitectonico-por-jacques-derrida/

Heidegger, Martin. 1994. Conferencias y Artículos. Traducido por Eustaquio Barjau. Barcelona: Ediciones del Serbal.

Heidegger, Martin. 2009. El Arte y el Espacio. Traducido por Jesús Adrián Escudero. Barcelona: Herder Editorial S.L.

Kahn, Louis. 1957. Architecture in the Tropicalmaking of Space. The Continual Renewal of Architecture comes from Changing Concepts of Space. Connecticut: Perspecta, The Yale Architectural Journal.

Maderuelo, Javier. 2008. La Idea del Espacio en la Arquitectura y el Arte Contemporáneos 1960-1989. Madrid: Ediciones Akal.

Merleau-Ponty, Maurice. 1993. Fenomenología de la Percepción. Barcelona: Planeta-De Agostini.

Morones Ibarra, José Rubén. 2004. «La Evolución de los Conceptos de Espacio y Tiempo». Revista Ingenierías 7(22): 55-63

Muntañola Thornberg, Josep. 2009. «Topogénesis: Fundamentos de una Nueva Arquitectura». Revista Arquitectonics: Mente, Territorio y Sociedad 18: 11-167

Ochoa, Felipe. 2000. «Isaac Newton: Una Mirada al Absolutismo». Revista Colombiana de Filosofía de la Ciencia 1(2-3):125-138. 
Rossi, Aldo. 1977. Para una arquitectura de tendencia. Escritos 1956-1972. Barcelona: Ed. Gustavo Gili.

Van De Ven, Cornelis. 1981. El espacio en Arquitectura. Barcelona: Ed. Científico-Médica.

Zumthor, Peter. 2004. Pensar La Arquitectura. Barcelona: Editorial Gustavo Gili.

Zumthor, Peter. 2006. Atmósferas. Barcelona: Editorial Gustavo Gili. 